\title{
VALIDATION OF THE RESPIRATORY TOXICS EXPOSURE SCORE (RTES) FOR CHRONIC OBSTRUCTIVE PULMONARY DISEASE SCREENING
}

\author{
PASCALE SALAMEH ${ }^{1}$, GEORGES KHAYAT ${ }^{2}$, and MIRNA WAKED ${ }^{3}$ \\ ${ }^{1}$ Lebanese University, Beirut, Lebanon \\ Faculty of Pharmacy, Faculty of Public Health \\ ${ }^{2}$ Hôtel Dieu de France Hospital \& Saint Joseph University, Beirut, Lebanon \\ Faculty of Medicine \\ ${ }^{3}$ Saint George Hospital \& University of Balamand, Beirut, Lebanon \\ Faculty of Medicine
}

\begin{abstract}
Objective: Our aim is to evaluate the validity of exhaled carbon monoxide $(\mathrm{CO})$ and of a newly-created score as markers of Chronic Obstructive Pulmonary Disease (COPD). Materials and Methods: The CO level was measured in a derivation subsample of a cross-sectional study and linked to COPD diagnosis; its predictors were evaluated, and a scale was constructed. It was evaluated in a validation subsample and in a clinical setting. Results: Individuals with COPD had higher CO levels than healthy individuals. $\mathrm{CO}$ level significant predictors were cigarettes per day, waterpipes per week, lower age, male gender, living close to diesel exhaust, heating home with the use of diesel, and having indoor family smokers. A score composed of CO predictors was able to significantly predict COPD (Ora = 4-7.5). Conclusions: Coupled with the clinical judgment of physicians, this scale would be an excellent low-cost tool for screening COPD, in absence of spirometry.
\end{abstract}

Key words:

Carbon monoxide, COPD, Biomarker

\section{BACKGROUND}

Carbon monoxide (CO) is considered to be a major factor contaminating the Earth's atmosphere, whether outdoor or indoor [1]. It has well-known toxic effects on human beings, but its long-term chronic effects are still not very well-explored. Harmful cardiovascular and neuropsychological effects were most frequently associated with chronic exposure to low levels of carbon monoxide and carboxyhemoglobin [2]. In people with pre-existing diseases, $\mathrm{CO}$ pollution alone may result in increased morbidity and mortality [3]. Moreover, although colorless and non-irritating [4], CO has some oxidative damaging effect on respiratory cells, probably involved in the initiation or promotion of the damage produced in chronic respiratory diseases [5]: it has been linked to respiratory symptoms and decreased respiratory volumes in women of Guatemala exposed to biomass exhaust [6]; CO level in air has also been associated with emergency visits in people with Chronic Obstructive Pulmonary Diseases (COPD) [7].

This work was funded by an unrestricted grant from Boehringer Ingleheim - Lebanon.

Received: June 16, 2011. Accepted: Sep 12, 2011.

Address reprint request to P. Salameh, Jdeidet El Meten, Chalet Suisse street, Ramza Azzam bldg, 5th floor, Beirut, Lebanon (e-mail: psalameh@ul.edu.lb or pascalesalameh1@hotmail.com). 
The main sources producing this contamination are engines using gasoline or diesel fuel during road transport and industrial processes using carbon compounds; these two are responsible for $80 \%$ of carbon monoxide emitted to the atmosphere [2]. CO is also a well-known indoor pollutant: it can originate as a result of the functioning of gas cookers and some heating systems, stationary combustion equipments, ingress of exhaust fumes from an attached garage, and proximity to heavily trafficked roads [8]. In a study performed in Guatemala, $\mathrm{CO}$ was used as a tracer for biomass combustion-related exposure [9]. Tobacco smoking is another important source of CO [10]; active cigarette and waterpipe smoking are both associated with $\mathrm{CO}$ increased exposure [11]. Moreover, $\mathrm{CO}$ is one of the most toxic substances present in the gas-phase of second-hand tobacco smoke [12]. It is noteworthy that combustion of any carboncontaining substance does not only produce $\mathrm{CO}$; it could also produce other toxic gases, such as nitrogen oxides, sulfur oxides, aldehydes and polycyclic aromatic hydrocarbons, in addition to particulate matter, the deleterious effect of which can be added to those of CO [13].

Nevertheless, CO can be considered as an easy and rapid biomarker, i.e. primarily of interest for the assessment of the exposure and early biological effects in epidemiology as well as occupational and environmental medicine [10]: in fact, microenvironment measurements of $\mathrm{CO}$ were shown to represent well the personal exposures of individuals within that microenvironment; $\mathrm{CO}$ can be measured accurately by instrumental means and it therefore represents an ideal tracer of exposure [8]. Since biomarkers are "observable endpoints in the continuum of events ranging from exposure to diseases" [14], CO is considered to be both an exposure and effect biomarker [15]. Its concentration in exhaled air can be affected by multiple factors, including external exposure extent, its own toxic effects on cells and tissues [15], in addition to the presence of endogenous diseases, such as asthma and COPD $[15,16]$. CO is now considered as a marker useful to detect some environmental and occupational risk factors, particularly those typical of cities [17]; CO is also used as a screener for smoking during smoking cessation procedure [18], and a biomarker of oxidative stress implicated in the pathogenesis of many pulmonary diseases including chronic inflammatory lung disorders such as asthma and COPD [19-21]. Moreover, smokers with COPD have higher levels of exhaled $\mathrm{CO}$ versus healthy smokers [22]. COPD, although a disease of major importance in public health, is diagnosed only after spirometric evaluation according to GOLD guidelines [23]. The use of exhaled biomarkers as a diagnostic tool for COPD was overviewed by van Beurden and his collaborators in 2002, and he suggested that there was a need for "standardization of the measurements, for comparison of COPD patients with healthy persons matched for age and smoking-status, for data on reproducibility and variability, for correlation of exhaled markers with other parameters and for intervention studies" [24]. To our knowledge, no studies were specifically conducted to fulfill this need for exhaled CO. Moreover, in non-clinical settings where neither $\mathrm{CO}$ measurement nor spirometry is available, it is conceptually sound to search for a surrogate measure for the $\mathrm{CO}$ level that would hypothetically serve to predict COPD. The aim of the current analysis is to confirm the validity of carbon monoxide level in exhaled air as a biomarker of COPD in the general population, and to explore the validity of a score reporting exposure to pulmonary toxics as a marker for screening COPD in both epidemiological and clinical settings.

\section{MATERIALS AND METHODS}

\section{Design and setting}

Study 1: A cross-sectional study was carried out between October 2009 and September 2010, using a multistage cluster sample all over Lebanon. Lebanese residents aged 40 years and above were enrolled in the study, with no exclusion criteria. Additional details are presented in another publication [25]. 
Study 2: A case-control study was performed between July 2009 and June 2010, comparing a group of patients with COPD from two tertiary care hospitals in Beirut with a control group. Additional details of the study are also presented in another publication [26].

\section{Procedures}

In both studies, after an oral informed consent, subjects had a prebronchodilator spirometry in the presence of a trained technician and answered a standardized questionnaire. After the administration of two puffs of bronchodilator (Combivent ${ }^{\circledR}$ ), a postbronchodilator spirometry was performed. The questionnaire comprised questions about sociodemographic characteristics, detailed active and passive smoking history, in addition to environmental and occupational toxic exposures questions. Moreover, carbon monoxide measurement was performed in a subsample of the first study population (derivation sample); the measurement was performed using a $\mathrm{CO}$ - Tester - NG, F.I.M. Every individual had to perform the measurement three times, and the best result was recorded.

\section{Statistical analysis}

For both studies, data entry was completed by independent lay persons that were unaware of the objectives of the study. Statistical analysis was performed using SPSS software, version 13.0. A p-value of 0.05 was considered significant. For continuous variables in the comparison of the groups, we used the Student's test for variables with adequate normal distribution. For non-normally distributed continuous variables and for non-continuous quantitative and ordinal variables, the Mann-Whitney test was used. For categorical variables, the Chi-square and Fisher's exact tests were used, when applicable. A linear trend test was applied to test for dose-effect relationships.

Dependent variables were: disease-related variables such as being diagnosed with COPD or not, chronic bronchitis, and respiratory symptoms. Independent variables were cigarette and waterpipe current and previous smoking, "toxics and fumes" occupational exposure, exposure to selected outdoor (living next to a busy road and living next to a local power plant - a diesel exhaust source) and indoor (heating home by gas, wood, or diesel, hot-air conditioner and passive smoking) pollutants. The carbon monoxide level was subsequently used as a dependent and an independent variable.

Multivariate analyses were carried out to evaluate predictors of dependent variables, taking into account potential confounding variables that had a $\mathrm{p}$-value $<0.20$ in bivariate analysis (gender, residency, age, height, weight, body mass index, education, work status, marital status) and independent variables cited above. When the dependent variable was continuous, a stepwise linear regression was applied to find out its predictors, after ensuring applications conditions (residuals linearity, model adequacy to data, and co-linearity diagnostics). This regression of predictors served to generate a score of exposure to toxic substances in the derivation subsample.

The above-mentioned score was later dichotomized according to the median. A kappa agreement measure was then calculated to evaluate the concordance between the dichotomous $\mathrm{CO}$ level and the toxic exposure score. In addition, sensitivity, specificity, positive predictive value and negative predictive value of the dichotomous score with respect to the dichotomous $\mathrm{CO}$ level were calculated.

Afterwards, in the validation subsample of study 1, a logistic regression was chosen because the dependent variable was dichotomous (disease variable; Chronic Obstructive Pulmonary Disease (COPD) and Chronic Bronchitis (CB)), after ensuring model adequacy to data by the Hosmer-Lemeshow test: a stepwise descendent likelihood ratio logistic regression was applied, and the final model was retained, the score of toxic exposure being the major independent variable. Point estimates of the ORa, 95\% confidence intervals and $p$-values were presented. Similar methods were used in study 2. 


\section{RESULTS}

\section{CO level description (Subsample 1 of study 1)}

In the subsample of study 1 where the $\mathrm{CO}$ level was measured $(n=652)$, CO had a minimum of 2 parts per million (ppm) and a maximum of $93 \mathrm{ppm}$. The CO level was then divided into quartiles, giving the following distribution: (2-6 ppm) 29\%, (7-10 ppm) 25.6\%, (11-20 ppm) 20.7\% and (20-95 ppm) $24.7 \%$.

\section{CO level as a biomarker of respiratory diseases} and symptoms (Subsample 1 of study 1 )

Mean CO levels differences in the presence or absence of the diseases and symptoms are presented in Figure 1. We note that the $\mathrm{CO}$ level did not significantly differ between a patient with asthma and other individuals, i.e. the subgroup encompassing healthy individuals and those with respiratory diseases other than asthma (16.76 vs. 15.23 ; $\mathrm{p}=0.247)$. In healthy individuals, the mean CO level was $13.04(\mathrm{SD}=11.62)$.

The CO level was found to be an independent predictor of respiratory diseases: every unit of the $\mathrm{CO}$ level increase was associated with increased risk of COPD $(\mathrm{OR}=1.055$; $\mathrm{p}<0.001)$. Moreover, the CO level units were also associated with increased risk of $\mathrm{CB}(\mathrm{OR}=1.033 ; \mathrm{p}<0.001)$,

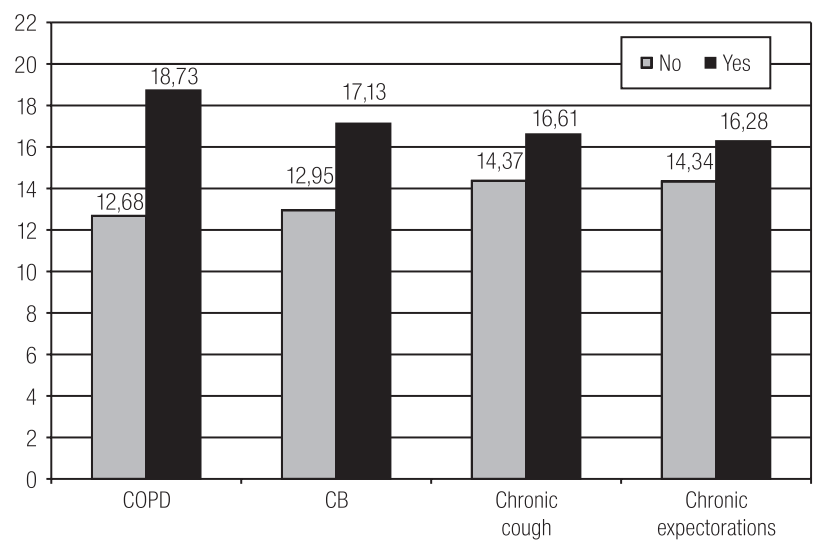

Fig. 1. Carbon monoxide level in chronic obstructive pulmonary disease (COPD), chronic bronchitis (CB), chronic cough and expectorations. chronic cough $(\mathrm{OR}=1.030 ; \mathrm{p}=0.001)$ and chronic sputum production $(\mathrm{OR}=1.021 ; \mathrm{p}=0.006)$.

In Table 1, we present figures for dose-effect relationships between the $\mathrm{CO}$ levels and respiratory diseases and symptoms. Moreover, an inverse dose-effect relationship was also found between the $\mathrm{CO}$ level and the ratio of post-bronchodilator FEV1/FVC, reflecting a higher CO level in more severe obstruction: $r=-0.149(p<0.001)$. Analogous results were found in the COPD patients subgroup, $\mathrm{r}=-0.115(\mathrm{p}=0.005)$; and what is more, in this subgroup, individuals treated with inhaled corticosteroids had a CO level that was lower than the non-treated ones (8.70 vs. $17.80 ; p<0.001)$.

\section{CO level predictors (Subsample 1 of study 1 )}

In Table 2, we present CO level predictors in the general population subsample where the $\mathrm{CO}$ level was measured $(\mathrm{n}=652)$. The global correlation coefficient of the model with the CO level is 0.699 , with an $\mathrm{R}^{2}=0.489$, and an adjusted $\mathrm{R}^{2}=0.483$. The ANOVA of the final model gave highly significant results $(\mathrm{p}<0.001)$, with satisfactory residuals linearity and co-linearity diagnostics. We found that the $\mathrm{CO}$ level was predicted by age, cigarette and waterpipe current smoking, living next to a local power plant, exposure to passive smoking at home, and heating home by diesel ( $\mathrm{p}<0.05$ for all; Table 2$)$.

\section{Respiratory toxics exposure score (RTES) creation (Subsample 1)}

In the subsample 1 where the $\mathrm{CO}$ level was measured ( $n=652$ ), based on the previous regression, a score for respiratory toxics exposure was created. Its equation was the following:

$$
\begin{gathered}
\text { RTES }=19.20+(0.537 \times \text { cigarettes } / \text { day }) \\
+(2.359 \times \text { powerplant })-(0.121 \times \text { age })-(2.813 \times \text { gender })+[1] \\
(2.138 \times \text { smokinside })+(2.319 \times \text { dieselheat }) \\
+(0.372 \times \text { waterpipe } / \text { week }) .
\end{gathered}
$$


Table 1. CO level and dose-effect relationship

\begin{tabular}{lcccc}
\hline \multicolumn{1}{c}{ CO level class } & Prevalence of COPD & Prevalence of CB & Prevalence of cough & $\begin{array}{c}\text { Prevalence } \\
\text { of expectorations }\end{array}$ \\
\hline $2-6 \mathrm{ppm}$ & $3.4 \%$ & $22.7 \%$ & $10.6 \%$ & $16.4 \%$ \\
$7-10 \mathrm{ppm}$ & $12.6 \%$ & $26.2 \%$ & $19.8 \%$ & $22.8 \%$ \\
$11-20 \mathrm{ppm}$ & $16.9 \%$ & $29.0 \%$ & $24.4 \%$ & $27.4 \%$ \\
$21-95 \mathrm{ppm}$ & $18.1 \%$ & $37.7 \%$ & $20.5 \%$ & $24.8 \%$ \\
p-value for trend & $<0.001$ & 0.011 & 0.004 & 0.025 \\
\hline
\end{tabular}

$\mathrm{CO}$ - carbon monoxide; $\mathrm{COPD}$ - chronic obstructive pulmonary disease; $\mathrm{CB}$ - chronic bronchitis.

Table 2. Carbon monoxide level predictors

\begin{tabular}{lccc}
\hline \multicolumn{1}{c}{ Predictor } & Beta & p-value & 95\% CI of beta \\
\hline Cigarettes smoked per day (n) & 0.537 & $<0.001$ & $0.482 ; 0.595$ \\
Waterpipes smoked per week (n) & 0.372 & 0.009 & $0.012 ; 0.562$ \\
Age (years) & -0.121 & $<0.001$ & $-0.191 ;-0.069$ \\
Female gender & -2.813 & $<0.001$ & $-4.233 ;-1.394$ \\
Lives near a local power plant & 2.359 & 0.002 & $0.873 ; 3.844$ \\
Family smokers smoke indoors & 2.138 & 0.002 & $0.415 ; 2.872$ \\
Heating home with diesel fuel & 2.319 & 0.002 & $0.864 ; 3.774$ \\
\hline
\end{tabular}

In this equation: [cigarettes/day: number of cigarettes/day; powerplant: living (1) or no (0) near a local power plant; age: age in years; gender: (1) if male and (2) if female; smokinside: home smokers smoke inside (1) or no (0); dieselheat: heating home by diesel (1) or not (0); waterpipe/week: number of waterpipes / week].

A correlation coefficient $(\mathrm{r}=0.697)$ was found between the score and the $\mathrm{CO}$ level in parts per million.

\section{RTES validation (Subsample 2 of study 1; study 2)}

Afterwards, this score was used in the validation subsample 2 of study 1 ( $n=1293)$, as an independent quantitative variable for predicting COPD: each unit increase in the RTES causes an increase of 1.13 in the ORa for COPD (Table 3); for CB, an identical ORa $=1.13$ was found. Similar results were found for study 2 (clinical setting; $\mathrm{n}=738: 211$ COPD and 527 controls): ORa $=1.15$ (1.111.18) $(\mathrm{p}<0.001)$ for COPD and ORa $=1.14(1.11-1.18)$ $(\mathrm{p}<0.001)$ for $\mathrm{CB}$, if the score is considered as a quantitative variable.

\section{RTES binary classification and validation}

\section{(Subsamples 1\&2 of study 1; study 2)}

RTES distribution in the subsample 1 of study 1 gave a median of 12.16. It was further classified as a binary exposure variable (RTES01) using 12 as the threshold value: individuals were considered exposed to respiratory toxics if they had a score equal to 12 or higher. Moreover, when dichotomizing the $\mathrm{CO}$ level around its median (=10 ppm), we found an acceptable agreement coefficient between the RTES01 and the CO level (kappa $=0.538 ; \mathrm{p}<0.001)$. In this case, the sensitivity of RTES01 was found to be $77.54 \%$, 
Table 3. Toxic exposure score (RTES) association with chronic obstructive pulmonary disease (COPD)

\begin{tabular}{lccc}
\hline \multicolumn{1}{c}{ Disease correlates } & ORa & p-value & 95\% CI of ORa \\
\hline Higher age class & 2.31 & $<0.001$ & $1.98-2.70$ \\
Family history of respiratory disease & 1.98 & 0.015 & $1.14-3.42$ \\
Previous waterpipe smoking & 3.48 & $<0.001$ & $1.75-6.94$ \\
Previous cigarette smoking & 4.37 & $<0.001$ & $2.66-7.19$ \\
Toxic exposure score (RTES) & 1.13 & $<0.001$ & $1.10-1.16$ \\
\hline
\end{tabular}

ORa — odds ratio adjusted.

Table 4. Binary toxic exposure score (RTES01) association with chronic obstructive pulmonary disease (COPD)

\begin{tabular}{lccc}
\hline \multicolumn{1}{c}{ Disease correlates } & ORa & p-value & 95\% CI of ORa \\
\hline Higher age class & 2.18 & $<0.001$ & $1.86-2.56$ \\
Male gender & 1.69 & 0.107 & $0.89-3.23$ \\
Family history of respiratory disease & 2.00 & 0.010 & $1.19-3.39$ \\
Unemployed & 2.22 & 0.032 & $1.08-4.55$ \\
Previous waterpipe smoking & 2.77 & 0.003 & $1.41-5.43$ \\
Previous cigarette smoking & 3.22 & $<0.001$ & $1.99-5.19$ \\
Binary toxic exposure score (RTES01) & 4.91 & $<0.001$ & $2.98-8.08$ \\
\hline
\end{tabular}

ORa - Odds Ratio Adjusted.

while specificity was $76.24 \%$, in addition to positive predictive value $(77.84 \%)$ and negative predictive value $(75.93 \%)$. This binary variable (RTES01) was further tested in subsample 2 of study 1 and presented in Table 4 . In the general population, the RTES binary classification was strongly associated with COPD (ORa 4.91; $\mathrm{p}<0.001)$. Moreover, RTES01 was also found to strongly correlate with chronic respiratory symptoms: $\mathrm{CB}(\mathrm{ORa}=4.41 ; \mathrm{p}<0.001)$, chronic cough $(\mathrm{ORa}=3.19 ; \mathrm{p}<0.001)$ and expectorations $(3.60 ; p<0.001)$.

In study 2 (case-control; clinical setting), if the score was considered as a dichotomous variable (RTES01), we obtained a very strong association with respiratory diseases: ORa $=7.91(4.54-13.78)(\mathrm{p}<0.001)$ for predicting COPD. Moreover, RTES01 was also found to strongly correlate with $\mathrm{CB}(\mathrm{ORa}=7.49 ; \mathrm{p}<0.001)$, chronic cough $(\mathrm{ORa}=5.28$; $\mathrm{p}<0.001)$ and expectorations $(5.52 ; \mathrm{p}<0.001)$.

\section{DISCUSSION}

In this study, as expected, we found that individuals with COPD and respiratory symptoms had CO levels that were higher than healthy individuals. These results were confirmed by a dose-effect relationship: with higher levels of $\mathrm{CO}$ in exhaled air, there was an incremental increase in the prevalence of COPD and respiratory symptoms. These results are similar to those reported by other researchers: in Guatemala, the CO level was correlated with chronic respiratory symptoms and volumes; but none of the women had COPD [6]. As a biomarker of effect, the biological plausibility of $\mathrm{CO}$ effect is known, since it can be a marker of oxidative damage, the latter being involved in COPD pathogenesis $[5,19,20]$. As for a biomarker of exposure, CO level significant predictors were the number of cigarettes smoked per day, the number of waterpipes smoked per week, lower age, male gender, in addition to living close to a local power plant 
(a diesel exhaust source), heating home with diesel fuel, and having family smokers who smoke indoors. The factors we found were well-known sources of CO [2,8,10,12]; waterpipe smoking association with $\mathrm{CO}$ has also been previously reported by ourselves [11] and others [27]. Several of those factors are also known risk factors for COPD: cigarette smoking [28,29], waterpipe smoking [26], male gender [25], biomass fuel combustion [30], and passive smoking [31,32]. Thus, we were able to confirm the close relationship between the $\mathrm{CO}$ level, its predictors, and COPD. The elevation in the CO level can be due to exposure to incomplete combustion of carbon compounds, oxidative stress at the lung level, or both.

In the validation subsample of the epidemiological setting, we showed that a score composed of $\mathrm{CO}$ level predictors was able to predict COPD in a significant manner, whether considered as a quantitative variable or as a dichotomous variable. This was true and even stronger manifested in clinical settings. Although our strategy resembles that of Meijer et al., who developed a model for COPD prediction based on medical and work-related questions in an occupational setting [33], this is - to our knowledge - the first time a scale has been constructed based on the $\mathrm{CO}$ level prediction of COPD. Coupled with the diagnosis of the physician based on clinical symptoms, we expect this scale to be an excellent tool in screening for COPD, in the absence of spirometry. This could be considered a low-cost strategy to detect individuals marked with high risk of COPD.

Additional studies that take into consideration the clinical presentation of the patient would be necessary to further validate COPD prediction; the value of this new scale should also be tested in prospective studies. The limitations of our study include a possibility of selection bias in the cross-sectional study, and of information bias coupled with the questionnaire we used. However, the fact that our results were confirmed in both the epidemiological and clinical settings would lead us to override these risks. Furthermore, the lack of significant association of the $\mathrm{CO}$ level with asthma, the demonstrated dose-effect relationships and the multivariate analyses are considered strong points of this work.

\section{CONCLUSION}

In conclusion, we were able to create and validate a scale that would be used in clinical and epidemiological testing, as a tool to screen for COPD. Further studies, particularly taking into account the clinical symptoms of the individual, are necessary to evaluate its validity as a marker for COPD diagnosis.

\section{REFERENCES}

1. Koistinen K, Kotzias D, Kephalopoulos S, Schlitt C, Carrer P, Jantunen, et al. The INDEX project: executive summary of a European Union project on indoor air pollutants. Allergy 2008;63(7):810-9. DOI: 10.1016/j.envpol.2008.06.031.

2. Téllez J, Rodríguez A, Fajardo A. Carbon monoxide contamination: an environmental health problem. Rev Salud Publica (Bogota) 2006;8(1):108-17 [in Spanish]. DOI: 10.1590/S012400642006000100010 .

3. Wright J. Chronic and occult carbon monoxide poisoning: we don't know what we're missing. Emerg Med J 2002;19(5): 386-90. DOI: 10.1136/emj.19.5.386.

4. Bernstein JA, Alexis N, Bacchus H, Bernstein IL, Fritz P, Horner E, et al. The health effects of nonindustrial indoor air pollution. J Allergy Clin Immunol 2008;121:585-91. DOI:10.1016/j.jaci.2007.10.045.

5. Yang W, Omaye ST. Air pollutants, oxidative stress and human health. Mutation Research 2009;674:45-54. DOI:10.1016/ j.mrgentox.2008.10.005.

6. Smith-Sivertsen T, Diaz E, Pope D, Lie RT, Diaz A, McCracken J, et al. Effect of Reducing Indoor Air Pollution on Women's Respiratory Symptoms and Lung Function: The RESPIRE Randomized Trial, Guatemala. Am J Epidemiol 2009; 17(2):211-21. DOI: 10.1093/aje/kwp100. 
7. Sunyer J, Saez M, Murillo C, Castellsague J, Martinez F, Anto JM. Air pollution and emergency room admissions for chronic obstructive pulmonary disease: a 5-year study. Am J Epidemiol 1993;137:701-5.

8. Harrison RM, Thornton CA, Lawrence RG, Mark D, Kinnersley RP, Ayres JG. Personal exposure monitoring of particulate matter, nitrogen dioxide, and carbon monoxide, including susceptible groups. Occup Environ Med 2002;59:671-9. DOI: $10.1136 /$ oem.59.10.671.

9. Naeher LP, Smith KR, Leaderer BP, Neufeld L, Mage DT. Carbon monoxide as a tracer for assessing exposures to particulate matter in wood and gas cookstove households of highland Guatemala. Environ Sci Technol 2001;35(3):575-81.

10. Scherer G. Carboxyhemoglobin and thiocyanate as biomarkers of exposure to carbon monoxide and hydrogen cyanide in tobacco smoke. Exp Toxicol Pathol 2006;58:101-24. DOI: 10.1016/j.etp.2006.07.001.

11. Salameh P, Aoun Bacha Z, Waked M. Saliva Cotinine and Exhaled Carbon Monoxide in Real Life Waterpipe Smokers: A Post Hoc Analysis. Tob Use Insights 2009;2:1-10.

12. Goniewicz ML, Czogała J, Kośmider L, Koszowski B, Zielińska-Danch W, Sobczak A. Exposure to carbon monoxide from second-hand tobacco smoke in Polish pubs. Cent Eur J Public Health 2009;17(4):220-2.

13. Pierson W, Koenig J, Bardana E. Potential adverse health effects of wood smoke. West J Med 1989;151:339-42.

14. Ward Jr JB, Henderson RE. Identification of needs in biomarker research. Environ Health Perspect 1996;104:895-900.

15. Scherer G. Biomonitoring of inhaled complex mixtures Ambient air, diesel exhaust and cigarette smoke. Exp Toxicol Pathol 2005;57:75-110.

16. Ece A, Gürkan F, Haspolat K, Derman O, Kırbas G. Passive smoking and expired carbon monoxide concentrations in healthy and asthmatic children. Allergol Immunopathol 2000;28:255-60.

17. Bono R, Piccioni P, Traversi D, Degan R, Grosa M, Bosello G, et al. Urban air quality and carboxyhemoglobin levels in a group of traffic policemen. Sci Total Environ 2007;376:10915. DOI:10.1016/j.scitotenv.2007.01.086

18. Chatkin G, Chatkin JM, Aued G, Petersen GO, Jeremias ET, Thiesen FV. Evaluation of the exhaled carbon monoxide levels in smokers with COPD. J Bras Pneumol 2010;36(3):332-8. DOI: $10.1590 / S 1806-37132010000300011$.

19. Montuschi P, Kharitonov S, Barnes P. Exhaled carbon monoxide and nitric oxide in COPD. Chest 2001;120:496-501. DOI: $10.1378 /$ chest.120.2.496

20. Horvath I, Loukides S, Wodehouse T, Kharitonov SA, Cole PJ, Barnes PJ. Increased levels of exhaled carbon monoxide in bronchiectasis: a new marker of oxidative stress. Tho$\operatorname{rax} 1998 ; 53: 867-70$.

21. Repine JE, Bast A, Lankhorst I. Oxydative stress in chronic obstructive pulmonary disease. Am J Respir Crit Care Med 1997;156:341-57.

22. Jiménez-Ruiz CA, Masa F, Miravitlles M, Gabriel R, Viejo JL, Villasante C, et al. Smoking characteristics: differences in attitudes and dependence between healthy smokers and smokers with COPD. Chest 2001;119(5):1365-70. DOI: 10.1378/chest.119.5.1365.

23. Global initiative for chronic Obstructive Lung Disease (GOLD). Global Strategy for the Diagnosis, Management, and Prevention of Chronic Obstructive Pulmonary Disease (updated 2009) [cited 2011 Sept]. Available at URL: http://www.gold.com.

24. Beurden WJ van, Dekhuijzen PN, Smeenk FW. Exhaled biomarkers in COPD: their potential role in diagnosis, treatment and prognosis. Monaldi Arch Chest Dis 2002;57(5-6): 258-67.

25. Waked M, Khayat G, Salameh P. Chronic Obstructive Pulmonary Disease Prevalence in Lebanon: a Cross-sectional descriptive study. Thorax. In press 2011.

26. Salameh P, Khayat G, Waked M, Dramaix M. Waterpipe smoking and dependence are associated Chronic Obstructive Pulmonary Disease (COPD): a case control study. Rev Mal Respir. In press 2011.

27. Maziak W, Rastam S, Ibrahim I, Ward KD, Shihadeh A, Eissenberg, T. CO exposure, puff topography, and 
subjective effects in waterpipe tobacco smokers. Nicotine Tob Res 2009;11(7):806-11. DOI: 10.1093/ntr/ntp066.

28. Fletcher CM, Peto R. The natural history of chronic airflow obstruction. BMJ 1977;1:1645-8.

29. Griffith KA, Sherrill DL, Siegel EM, Manolio TA, Bonekat HW, Enright PL. Predictors of loss of lung function in the elderly. The cardiovascular health study. Am J Respir Crit Care Med 2001;163:61-8.

30. Zhang JJ, Smith KR. Household Air Pollution from Coal and Biomass Fuels in China: Measurements, Health Impacts, and Interventions. Environ Health Perspect 2007;115:848-55. DOI: $10.1289 /$ ehp. 9479.
31. Committee on Passive Smoking. The physicochemical and toxicological studies of environmental tobacco smoke. In: Committee on Passive Smoking, ed. Environmental tobacco smoke. 9th ed. Washington, DC: National Academy Press; 1986. p. 25-64.

32. US Department of Health and Human Services. Health effects of environmental tobacco smoke exposure. In: Shopland $\mathrm{D}$, ed. The health consequences of involuntary smoking. Washington: DC; 1986. p. 17-118.

33. Meijer E, Grobbee D, Heederick D. Health Surveillance for Occupational Chronic Obstructive Pulmonary Disease. J Occup Environ Med 2001;43:444-50.

This work is available in Open Access model and licensed under a Creative Commons Attribution-NonCommercial 3.0 Poland License - http://creativecommons.org/ licenses/by-nc/3.0/pl/deed.en. 